\title{
The occurrence of fluoride in South African groundwater: A water quality and health problem
}

\author{
E J Ncube* and CF Schutte \\ Department of Chemical Engineering, University of Pretoria, Pretoria, 0001; Republic of South Africa
}

\begin{abstract}
Groundwater is the most appropriate and widely used source of drinking water for many rural communities in South Africa. Pilot studies and surveys conducted by the Department of Water Affairs and Forestry (DWAF) indicated that there are a number of boreholes across the country that contain apart from fluoride, levels of nitrate, some heavy metals, total dissolved solids, sulphates and faecal coliforms (in some regions) that could pose a health risk if the water is used for drinking purposes. Very few boreholes have been tested for heavy metals or toxic organic substances. However, considering the levels of fluoride, in general, groundwater is of acceptable quality except for some areas in which elevated levels of natural groundwater fluoride occur. The study on which this paper is based was conducted to identify areas of high groundwater fluoride concentration in South Africa and to relate this to the occurrence of dental fluorosis in most communities using the groundwater for domestic use. Two sets of data were used. The fluoride data were obtained by extracting fluoride groundwater quality data from DWAF's Water Management Systems (WMS) database. STATISTICA and ARCVIEW were used to process the data. The dental fluorosis data were obtained from a field study conducted by the Department of Health. The degree of dental fluorosis was determined using Dean's classification criteria for dental fluorosis. The occurrence of dental fluorosis was observed in those areas in which fluoride levels were higher than the recommended guidelines for drinking water. The degree and severity of mottling in the subjects studied by the DOH team, corresponded with the level of fluoride in drinking water and the percentage morbidity of dental fluorosis varied from province to province, district to district and village to village.
\end{abstract}

Keywords: fluoride concentration; groundwater; fluorides; dental fluorosis; morbidity of dental fluorosis

\section{Introduction}

The beneficial attributes of fluorides to human health have been known for many years (WHO, 1970). When ingested at specific doses, the fluoride ion is beneficial to both bone and dental development in human beings. At correct intake levels it plays a very important role in the formation of teeth (Pontius, 1991). Too low fluoride intake levels during childhood may give rise to the occurrence of preventable dental caries in later years. Dental caries is a disease caused by specific bacteria harboured in dental plaque, fermenting carbohydrates to produce acids that can demineralise tooth enamel (Hammer, 1986). If this demineralization is allowed to continue, the enamel is penetrated permitting bacterial invasion and eventual loss of the tooth by decay in the absence of restorative dental care.

Too high fluoride intake normally gives rise to teeth mottling (dental fluorosis) and related problems. Chronic endemic fluorosis is a condition which is caused by an excess of fluorides in drinking water and which affects the calcification of the teeth, resulting in what is commonly known as dental fluorosis. Maughan-Brown in 1935 and Raubenheimer in 1938 first reported a study of the occurrence of mottled enamel in South Africa(WRC, 2001). In 1941, Ockerse produced three reports on human fluorosis in various regions of the former Union of South Africa. At that time 805 areas in which dental fluorosis occurred were known(Ockerse, 1947). The

* To whom all correspondence should be addressed.

Business address for correspondence:

Rand Water, P.O. Box 1127, Johannesburg, 2000

푱+271 682-0075; fax:+2711 682- 0733;

e-mail: encube@randwater.co.za

Received 28 April 2004; accepted in revised form 15 October 2004. majority of dental fluorosis sufferers (mainly blacks) in South Africa live in rural areas. Different studies have shown that the occurrence of dental fluorosis in the majority of cases in South Africa are related to the fluoride content of groundwater used for drinking purposes (McCaffrey 1993; Fayazi, 1994; Du Plessis, 1995; WRC, 2001).

The issue of whether and at what levels of concentration, to manage the fluoride ion concentrations in South Africa's public water supplies is a contentious one. While the Department of Water Affairs and Forestry (DWAF), as the custodian of the country 's water resources, manages the fluoride levels through the criteria set in its guidelines, (DWAF, 1996) and the South African Bureau of Standards (SABS) determines the specifications (SABS, 2001), the Department of Health proposes compulsory fluoridation of public water supplies (Anon, 1998). Similarly, the awareness of excess fluoride consumption through water has been increasing countrywide. (McCaffrey, 1993; Fayazi, 1994; Rudolph et al., 1995; Du Plessis, 1995; WRC, 2001).

One of the main issues is the lack of adequate information on the environmental and health impacts of fluoride locally. Most of the information is highly technical for the local people and no proper interventions have been made to increase awareness. Most of the environmental issues are addressed in a recent Water Research Commission report (WRC, 2004). There is also a lack of accurate information in a user-friendly format about the current status of fluoride in the country's groundwater resources. This paper addresses these gaps by assessing the groundwater fluoride data from the Water Management System Database housed at DWAF's Resource Quality Services Directorate, for the period 1996 to 2000 in order to establish the current occurrence of fluoride ion concentration levels in groundwater sources and the impact of dietary fluoride (from groundwater consumption) on dental health. As 


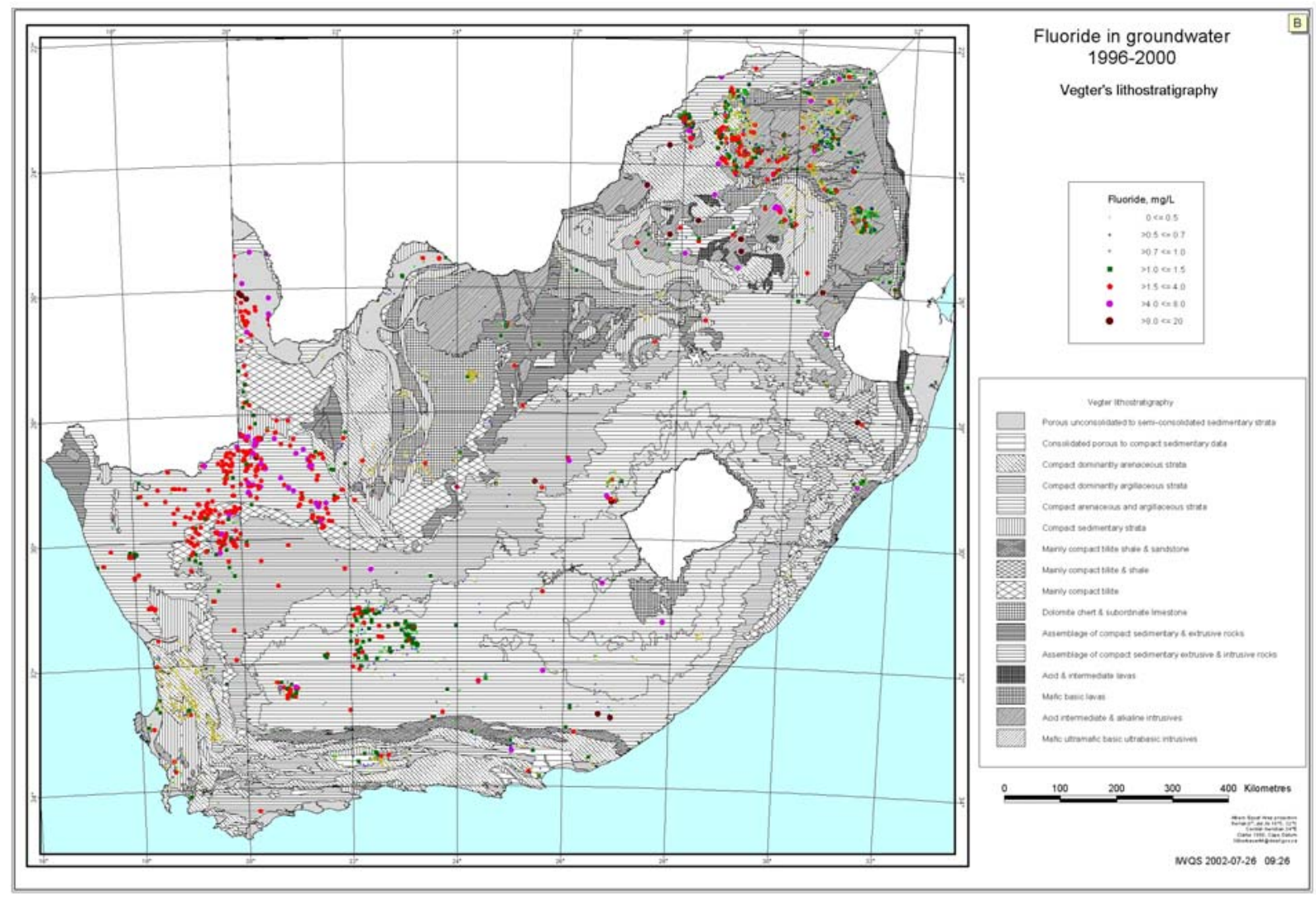

Figure I

Fluoride in groundwater 1996 - 2000

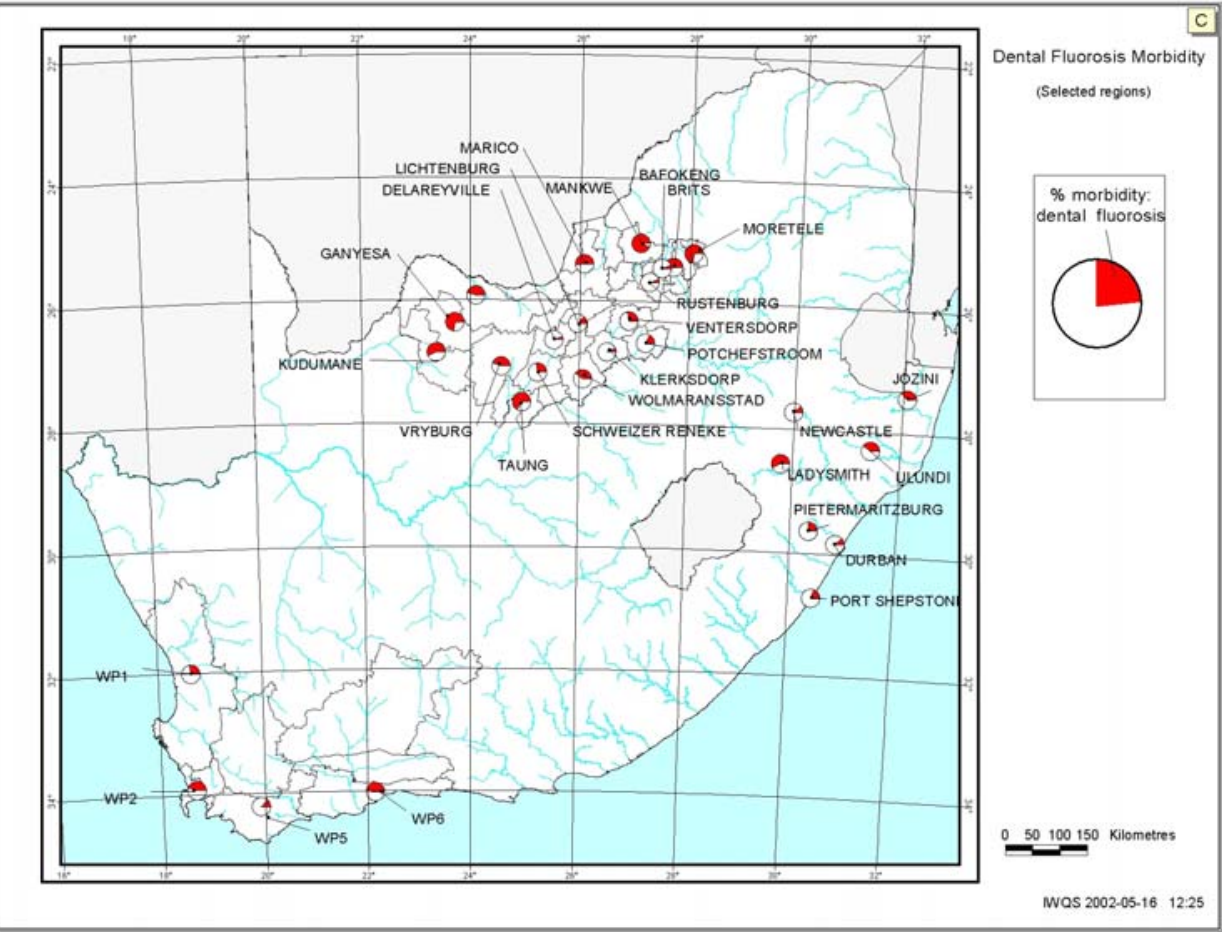

Figure 2

The distribution of $\%$ morbidity of dental fluorosis outcomes of this study, areas with fluoride ion concentrations lower or higher than those recommended for drinking water and the occurrence of dental fluorosis in selected provinces, are delineated. At the time of this study (Ncube and Schutte, 2002) dental fluorosis results from the Oral Health Care Survey conducted by DOH were available for a few provinces, hence the study of selected provinces and not the rest of the country. The fact that a province like Gauteng is served by reticulated water and there are no boreholes mainly used for drinking water purposes was taken into account. The degree of the severity of dental fluorosis is shown in terms of the percentage 
morbidity of dental fluorosis. This is overlain on a water quality map in order to assess the relationship between the occurrence of fluoride in groundwater and the incidences of dental fluorosis. Relevant recommendations based on the results of this study are also made. A detailed analysis of the factors that affect the occurrence of fluoride in groundwater and distribution of fluoride in groundwater are discussed in detail in Ncube and Schutte, 2002.

\section{Approach}

The fluoride data were extracted from DWAF's Water Management System (WMS) Database housed at the Resource Quality Services (RQS) directorate of DWAF. This constituted 14509 groundwater samples, including boreholes and springs. The data were screened for errors, incorrect reference codes, incorrect co-ordinates and number of fluoride ion concentrations reported for the station. A statistical package, STATISTICA, was used to calculate a fluoride median value for each unique groundwater source. This resulted in a summarised data set comprising 6042 values. Plotting these data on a map assessed the current status of fluoride ion distribution in the country (Fig. 1). This map was plotted using ARCVIEW and the available fluoride water quality data.

The dental fluorosis data were obtained from the National Department of Health (NDOH). These data were processed according to Wang et al.(1999), Table 1 , in order to obtain the \% morbidity of dental fluorosis. The results for the selected provinces are as shown in Tables 2, 3, 4 and 5. The results are based on the degree of mottling of the teeth as observed during the dental examinations. A comparison was made between the \% morbidity of dental fluorosis and the drinking water quality in selected provinces. The results are shown in Figs. 2 to 5.

\section{Results and discussion}

The current status of fluoride ion distribution in South African groundwater is provided in Fig. 1. The figure shows that the problems of high fluoride ion concentrations are currently concentrated in the Limpopo, Northern Cape, North-West and KwaZulu-Natal Provinces. These provinces have a high population still living in rural areas and prior to 1994 most of them used ground- and surface water for drinking purposes. A few cases were recorded in other parts of the country. The current situation of the fluoride distribution in the country is such that no clear demarcation can be made of areas deficient in fluoride since some areas have groundwater sources in which the fluoride ion concentrations are higher than the recommended limits for drinking water. This is an indication that the occurrence of low fluoride ion concentrations in groundwater is currently not a national problem. Many sources in the Limpopo, North-West, Northern Cape, Western Cape and KwaZulu-Natal Provinces are in need of partial defluoridation to the optimum level of fluoride concentration safe for drinking water purposes.
TABLE1

Criteria used for the interpretation of dental fluorosis results $\%$ Morbidity of dental fluorosis = $(B+C)$

\begin{tabular}{|l|l|}
\hline Class & Dental fluorosis symptoms \\
\hline A-Normal & No apparent abnormality \\
\hline $\begin{array}{l}\text { B-Slight(Questionable, } \\
\text { very mild, mild) }\end{array}$ & Yellowish teeth with slight erosion \\
\hline $\begin{array}{l}\text { C-Heavy (Moderate } \\
\text { and Severe) }\end{array}$ & $\begin{array}{l}\text { Extended erosion or mottling or } \\
\text { heavy damage to teeth. }\end{array}$ \\
\hline
\end{tabular}

\begin{tabular}{|l|c|c|c|c|c|}
\hline \multicolumn{7}{|c|}{$\begin{array}{c}\text { TABLE2 } \\
\text { Dental fluorosis by level of severity in the Free State (FS) Province } \\
\text { (Age group 12) }\end{array}$} \\
\hline Name of Place & Class A & Class B & Class C & B + C & $\%$ Morbidity \\
\hline FS-Region A & $34.5 \%$ & $62.2 \%$ & $2.5 \%$ & $64.7 \%$ & 64.70 \\
FS-Region B & $35.6 \%$ & $62.3 \%$ & $1.3 \%$ & $63.6 \%$ & 63.60 \\
FS-Region C & $66.1 \%$ & $29.1 \%$ & $3.0 \%$ & $32.1 \%$ & 32.10 \\
FS-Region D & $66.1 \%$ & $31.5 \%$ & $1.7 \%$ & $33.2 \%$ & 33.20 \\
FS-Region E & $66.5 \%$ & $29.7 \%$ & $1.7 \%$ & $31.4 \%$ & 31.40 \\
FS-Region F & $42.4 \%$ & $51.4 \%$ & $4.8 \%$ & $56.2 \%$ & 56.20 \\
\hline
\end{tabular}

TABLE3

Dental fluorosis by level of severity in the Western Cape (WC) Province (Age group 12)

\begin{tabular}{|l|c|c|c|c|c|}
\hline Name of Place & Class A & Class B & Class C & B + C & \%Morbidity \\
\hline WC-Boland- & $86.0 \%$ & $13.3 \%$ & $0 \%$ & $13.3 \%$ & 13.30 \\
$\quad$ Overberg Region & & & & & \\
WC- Metro & $54.5 \%$ & $42.1 \%$ & $2.2 \%$ & $44.3 \%$ & 44.30 \\
WC- South Cape & $46.5 \%$ & $39.2 \%$ & $10.7 \%$ & $48.7 \%$ & 48.70 \\
$\quad$ - Karoo & & & & & 27.90 \\
WC-West-Coast & $69.4 \%$ & $26.5 \%$ & $1.4 \%$ & $27.9 \%$ & 27.90 \\
\hline
\end{tabular}

TABLE4

Dental fluorosis by level of severity in the KwaZulu-Natal (KZN) Province (Age group 12)

\begin{tabular}{|l|c|c|c|c|c|}
\hline Name of Place & Class A & Class B & Class C & B + C & \%Morbidity \\
\hline Durban & $79.6 \%$ & $10.9 \%$ & $1.4 \%$ & $12.3 \%$ & 12.30 \\
Jozini & $50.7 \%$ & $34.7 \%$ & $2.5 \%$ & $37.2 \%$ & 37.20 \\
Ladysmith & $41.7 \%$ & $50.8 \%$ & $7.0 \%$ & $57.8 \%$ & 57.80 \\
Newcastle & $86.4 \%$ & $7.6 \%$ & $3.3 \%$ & $10.9 \%$ & 10.90 \\
Pietermaritzburg & $72.2 \%$ & $23.1 \%$ & $2.1 \%$ & $25.2 \%$ & 25.20 \\
Port Shepstone & $77.1 \%$ & $17.5 \%$ & $1.8 \%$ & $19.3 \%$ & 19.30 \\
Ulundi & $57.8 \%$ & $38.2 \%$ & $1.9 \%$ & $40.10 \%$ & 40.10 \\
\hline
\end{tabular}




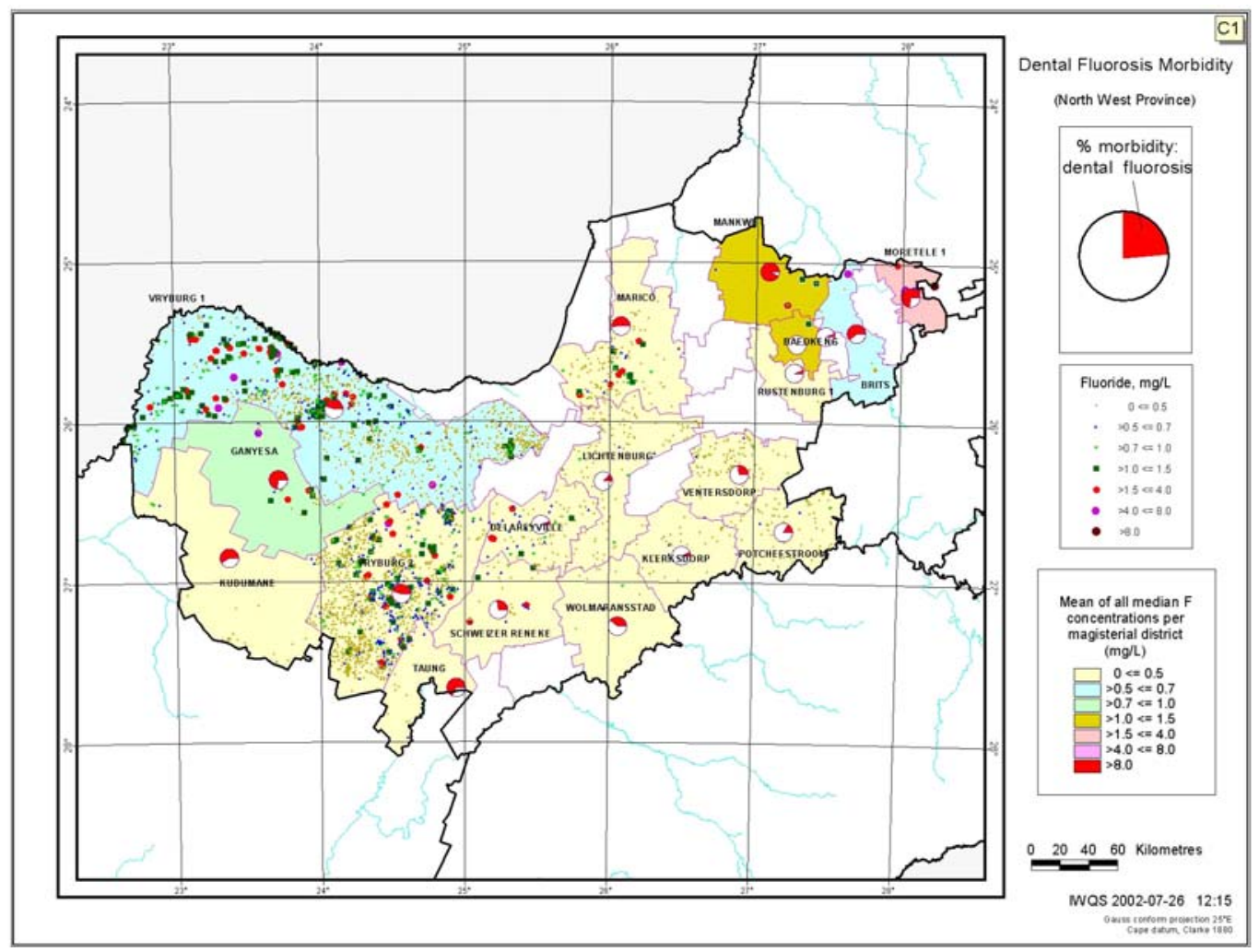

Figure 3

Dental fluorosis

morbidity (North

West Province)

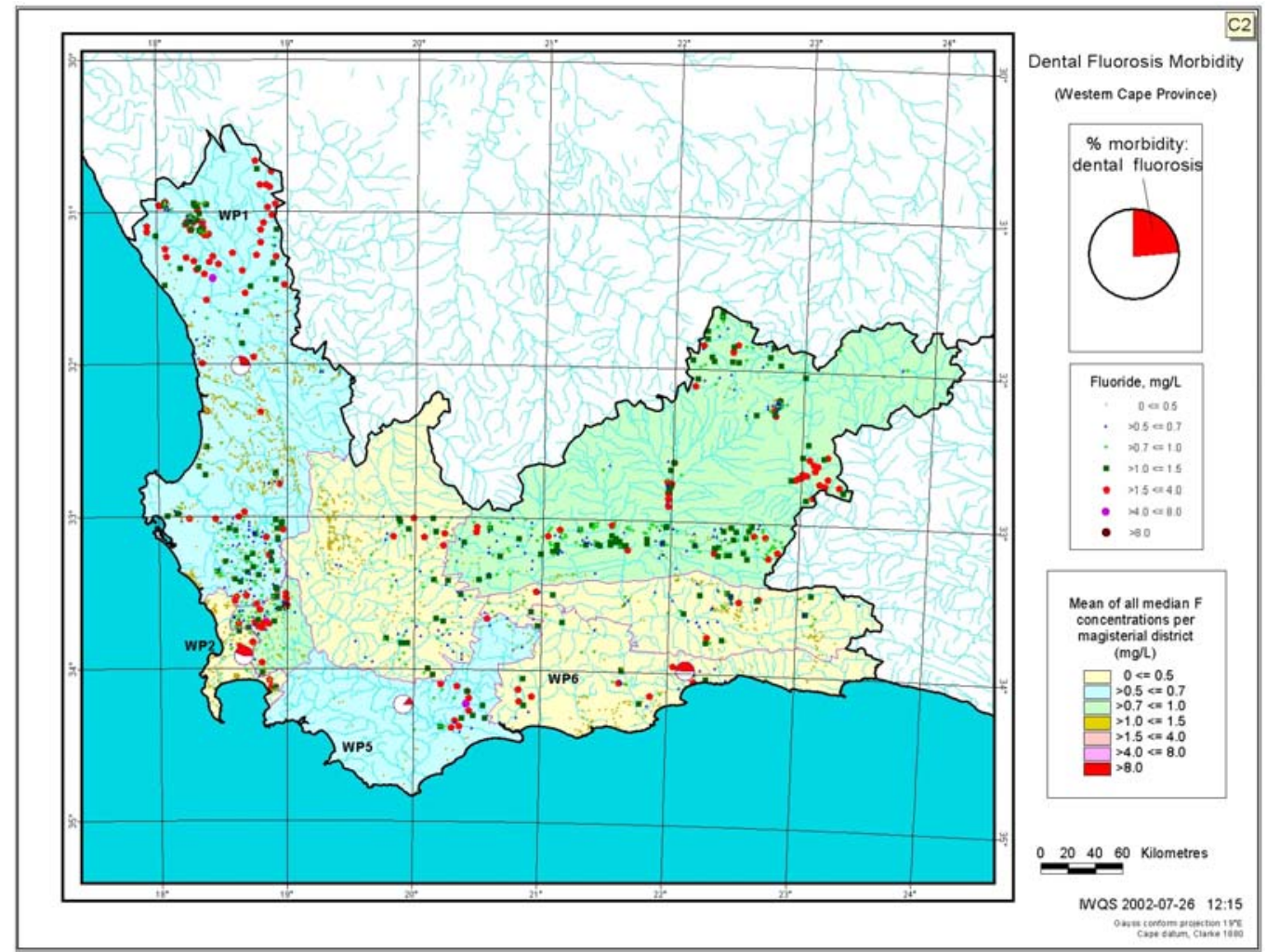

This must receive serious consideration if the water from those sources is being used for drinking purposes.

The results of the general investigations of fluorosis obtained by the data from the DOH are as presented in Tables 2, 3, 4 and 5. The criteria used to interpret the results are as presented in Table 1. adopted from Wang et al. (1999). The information on the depend- ency of communities on groundwater for use as drinking water is presented in Table 6. This was obtained from DWAF. This information was obtained in order to confirm the link between high fluoride levels in groundwater, the consumption of this fluoride contaminated water and the occurrence of dental fluorosis in the same areas. It should be noted that in a province where the 
Figure 5

Dental fluorosis morbidity (KwaZuluNatal)

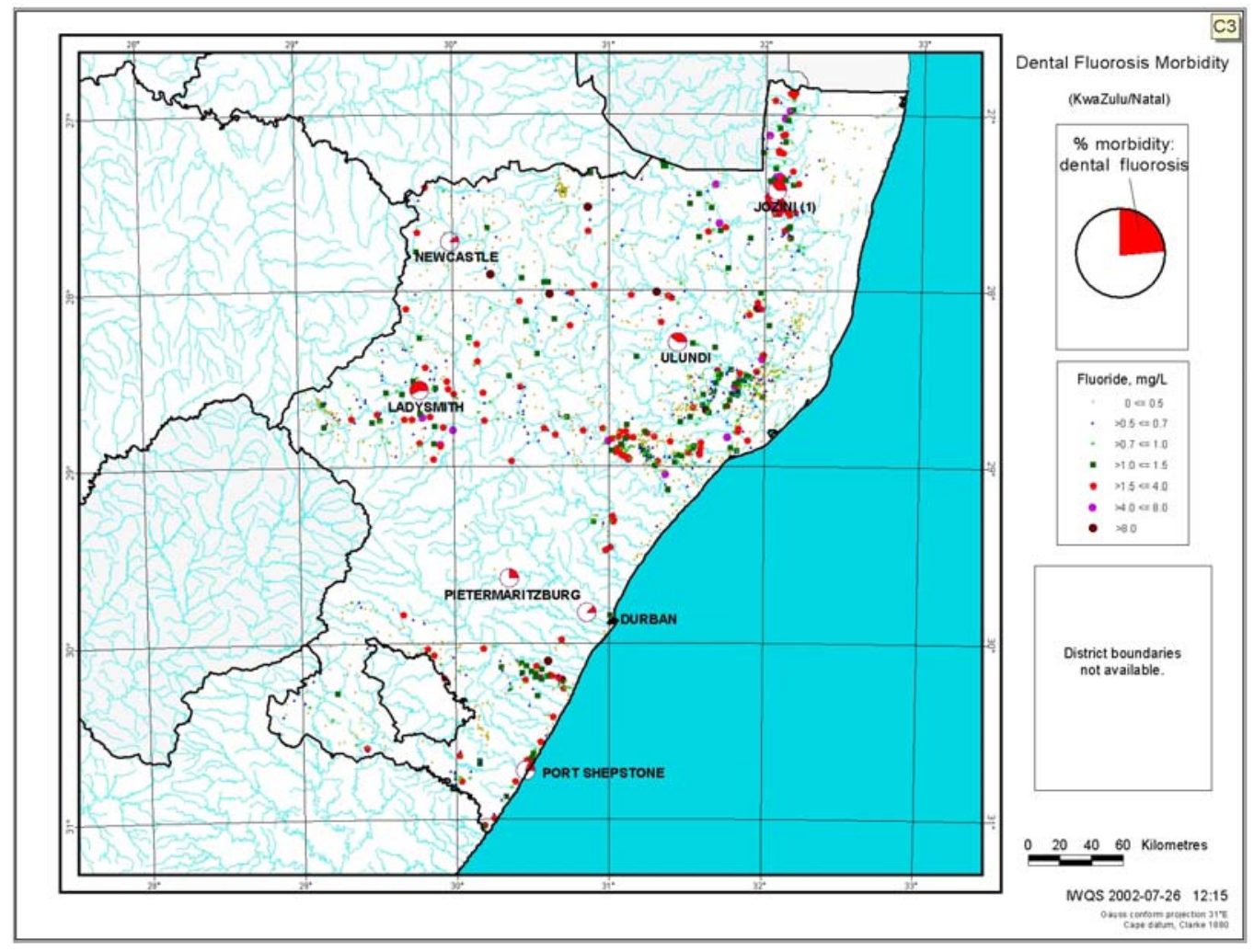

communities depend largely on groundwater for drinking water purposes like the North-West Province, the morbidity of dental fluorosis is high. However, it should be noted that due to the migratory nature of the South African population post-1994 some provinces like the Western Cape might show inconsistent results although it was confirmed that the Mitchell's Plain data are mostly for private boreholes. These boreholes might not necessarily be used for drinking water purposes but for other domestic uses such as general cleaning and irrigation purposes.

The distribution of dental fluorosis in selected provinces is shown in Figs. 2, 3, 4 and 5. The maps show the spatial distribution of the current \% morbidity of dental fluorosis for the Western Cape, North-West and KwaZulu-Natal Provinces. The fluoride data are overlain on each provincial map in order to correlate the level of the morbidity of dental fluorosis and fluoride levels in drinking water. It should be noted that differences exist in the morbidity of dental fluorosis among the areas investigated and this is true for the fluoride levels in groundwater sources. It was difficult to present the Free State Province data using the same format as the dental fluorosis data were reported in regions whose digital data were not available at the time of writing this paper.

From the results, a percentage morbidity of dental fluorosis as high as $97 \%$ was recorded in the North-West Province. In comparing the distribution of the \% morbidity of fluorosis with that of fluoride concentration in groundwater sources (Figs. 1 to 3), it is apparent that high morbidity of fluorosis is observed in areas where fluoride concentrations are extremely high and in most cases exceeding the
TABLE5

Dental fluorosis by level of severity in the North-West (NW) Province (Age group 12)

\begin{tabular}{|l|c|c|c|c|c|}
\hline Name of Place & Class A & Class B & Class C & B + C & \%Morbidity \\
\hline NW-Brits & $32.8 \%$ & $61.7 \%$ & $5.6 \%$ & $67.3 \%$ & 67.30 \\
NW-Delareyville & $80.7 \%$ & $5.8 \%$ & $0 \%$ & $5.8 \%$ & 5.80 \\
NW-Mafikeng & $97.7 \%$ & $0.9 \%$ & $0 \%$ & $0.9 \%$ & 0.90 \\
NW-Mogwase & $6.7 \%$ & $93.4 \%$ & $0 \%$ & $93.4 \%$ & 93.40 \\
NW-Moretele & $25.6 \%$ & $35.3 \%$ & $39.1 \%$ & $74.4 \%$ & 74.40 \\
NW-Potchefstroom & $82.8 \%$ & $17.2 \%$ & $0 \%$ & $17.2 \%$ & 17.20 \\
NW-Rustenburg & $81.9 \%$ & $5.8 \%$ & $0 \%$ & $5.8 \%$ & 5.80 \\
NW-Ganyesa & $26.7 \%$ & $54.9 \%$ & $18.4 \%$ & $73.3 \%$ & 73.30 \\
NW-Klerksdorp & $82.7 \%$ & $13.5 \%$ & $1.8 \%$ & $15.3 \%$ & 15.30 \\
NW-Kuruman & $42.3 \%$ & $57.7 \%$ & $0 \%$ & $57.7 \%$ & 57.70 \\
NW-Lichtenburg & $86.6 \%$ & $12.8 \%$ & $0.5 \%$ & $13.3 \%$ & 13.30 \\
NW-Schweizer & $71.7 \%$ & $26.6 \%$ & $1.6 \%$ & $28.2 \%$ & 28.20 \\
NW-Taung & $31.6 \%$ & $60.7 \%$ & $7.1 \%$ & $67.8 \%$ & 67.80 \\
NW-Ventersdorp & $73.3 \%$ & $20 \%$ & $6.7 \%$ & $26.7 \%$ & 26.70 \\
NW-Vryburg & $49.7 \%$ & $43.6 \%$ & $6.7 \%$ & $50.3 \%$ & 50.30 \\
NW-Zeerust & $47.8 \%$ & $48.6 \%$ & $2.1 \%$ & $50.7 \%$ & 50.70 \\
NW-Wolmaranstad & $61.1 \%$ & $33.4 \%$ & $5.6 \%$ & $39 \%$ & 39.00 \\
\hline
\end{tabular}

limits for drinking water. In towns and villages where the water quality problem in terms of fluoride ion concentration is less serious, the morbidity of fluorosis is comparatively low. It is evident from the maps that the occurrence of dental fluorosis and its morbidity correspond to the levels of fluoride ion concentrations in drinking water. The size of the shaded part (\% morbidity of dental fluorosis) in each area gives the idea of the general quality of drinking water consumed by the examined subjects. 


\begin{tabular}{|c|c|c|c|c|c|c|}
\hline \multicolumn{7}{|c|}{$\begin{array}{c}\text { TABLE } 6 \\
\text { Dependency of communities on groundwater for domestic purposes }\end{array}$} \\
\hline \multirow{2}{*}{$\begin{array}{l}\text { Province } \\
\text { Source }\end{array}$} & \multicolumn{2}{|c|}{ North-West } & \multicolumn{2}{|c|}{ Free State } & \multicolumn{2}{|c|}{ KwaZulu-Natal } \\
\hline & Communities & People & Communities & People & Communities & People \\
\hline Groundwater & 1063 & 1411707 & 72 & 122161 & 807 & 2416721 \\
\hline Surface water & 221 & 2099461 & 149 & 3097252 & 75 & 212698 \\
\hline Combined Source & 13 & 108593 & 30 & 139452 & 48 & 149685 \\
\hline None & - & - & & & & \\
\hline Unknown & - & - & & & 1563 & 5624304 \\
\hline Total & 1297 & 3619761 & 251 & 3340865 & 2493 & 8403408 \\
\hline \multicolumn{7}{|l|}{ Supply potential } \\
\hline Poor & 160 & 48733 & - & - & - & - \\
\hline Low & 207 & 330061 & 24 & 83380 & - & - \\
\hline Moderate & 341 & 1220101 & 99 & 905112 & 996 & 2590125 \\
\hline High & 266 & 1620011 & 124 & 2271450 & 558 & 1529404 \\
\hline Very high & 323 & 400855 & 4 & 80923 & 939 & 4283879 \\
\hline Total communities & 1297 & 3619761 & 251 & 3340865 & 2493 & 8403408 \\
\hline Total population & & 3619761 & & 3340865 & & 8403408 \\
\hline
\end{tabular}

\section{Conclusions}

Areas with high fluoride ion concentrations in their groundwater supplies and high percentage morbidity of dental fluorosis have been confirmed. Many of these sources require partial de-fluoridation if they are currently being used for drinking water purposes or the development of alternative water supplies as a matter of urgency. Proper research must be initiated into investigating cheap and technologically simple processes for small-scale removal of fluoride from fluoride-rich groundwater or developing alternative methods of supply in areas where there is such a problem especially in rural areas. The authors are aware of the techniques developed in other countries but South Africans need to develop techniques suitable for their local conditions and affordable by the lay person in the rural communities.

Since the occurrence of low fluoride ion concentrations in groundwater is not a national problem, fluoridation of groundwater is not advisable. Alternatives to water fluoridation should be looked into for such areas. These could include salt fluoridation, milk fluoridation, or the use of fluoride supplements such as fluoride drops or tablets or fluoridated vitamins. However, before these methods can be implemented much research needs to be carried out to test their relevance and feasibility in the South African context.

\section{Acknowledgement}

The authors would like to thank Mr Mike Silberbauer and his team for the unconditional assistance with the data extraction, quality control of the data and GIS expertise. Without their assistance this study would not have been possible. Thanks are also due to Dr Kroon and colleagues at the Department of Health for granting authority to access the dental fluorosis data.

\section{References}

ANONYMOUS (1998) Notice R797 of 12 June 1998. Regulations under the Health Act, 1977 (Act No. 53 of 1977). Schedule:
Regulations of fluoridating public water supplies. Republic of S. Afr. Government Gazette 396 (18960) 7-14.

DU PLESSIS JB (1995) What would be the maximum concentration of fluoride in water that would not cause dental fluorosis? Proc. Fluoride and Fluorosis. The Status of South African Research.Pilanesberg National Park, North West Province. 4.

DWAF (1996) South African Water Quality Guidelines for Domestic Use ( $1^{\text {st }}$ edn.).

FAYAZI M (1994) Regional groundwater investigation on the Northern Springbok flats. Department of Water Affairs and Forestry. Geohydrology, GH Report No. 3684 108-155.

GROBLER SR and DREYER AG (1988) Variations in the fluoride levels of drinking water in South Africa. S. Afr. Med. J. 73 217-219.

HAMMER MJ (1986) Need for fluoridation of desalinated water supplies. Aqua (London UK) 4 179-182.

McCAFFREY LP and WILLIS JP (1993) Distribution of fluoride-rich groundwater in the eastern parts of Bophuthatswana, relationship to bedrock and soils and constraints on drinking water supplies: a preliminary report. Africa Needs Ground Water. An International Ground Water Convention. 1 1-8.

NCUBE EJ and SCHUTTE CF (2002) The Distribution of Fluoride in South African Groundwater and the Impact thereof on Dental Health. M.Sc. dissertation submitted to the University of Pretoria.

OCKERSE T (1947) Endemic Fluorosis in South Africa. A Ph.D. thesis submitted to the University of Witwatersrand.

PONTIUS FW (1991) Fluoride regulation and water fluoridation. J. Am. Water Works Assoc. 83 (11)20-22, 96.

RUDOLPH MJ, MOLEFE M and CHIKTE OME (1995) Dental fluorosis with varying levels of fluoride in drinking water. J. Dental Res. 741012.

SABS (2001) Fluoride Standard for Drinking Water. SABS 241 (5 ${ }^{\text {th }}$ edn.).

WANG XC, KAWAHARA K and GUO XJ (1999) Fluoride contamination of groundwater and its impacts on human health in Inner Mongolia area, China. Aqua 48 (4) 146-153.

WRC (2001) Distribution of Fluoride-Rich Groundwater in the Eastern and Mogwase Regions of the Northern and North-West Province. WRC Report No. 526/1/01 1.1 - 9.85 Pretoria.

WRC (2004) Feasibility of Water Fluoridation for South Africa. WRC Report No TT 222/04, Pretoria. 